$41(1) \mid 2012$

Varia

\title{
Grigotá y Vitupue. En los albores de la historia chiriguana (1559-1564)
}

Grigotá et Vitupue. À l'aube de l'histoire chiriguana (1559-1564)

Gigotá and Vitupue. At the dawn of Chiriguana history (1559-1564)

Isabelle Combès

\section{CpenEdition}

Journals

Edición electrónica

URL: http://journals.openedition.org/bifea/1078

DOI: $10.4000 /$ bifea. 1078

ISSN: 2076-5827

Editor

Institut Français d'Études Andines

Edición impresa

Fecha de publicación: 1 enero 2012

Paginación: 57-79

ISSN: 0303-7495

Referencia electrónica

Isabelle Combès, «Grigotá y Vitupue. En los albores de la historia chiriguana (1559-1564) », Bulletin de I'Institut français d'études andines [En línea], 41 (1) | 2012, Publicado el 01 agosto 2012, consultado el 06 noviembre 2020. URL : http://journals.openedition.org/bifea/1078 ; DOI : https://doi.org/10.4000/ bifea.1078

\section{(c) (i) $\odot$}

Les contenus du Bulletin de l'Institut français d'études andines sont mis à disposition selon les termes de la licence Creative Commons Attribution - Pas d'Utilisation Commerciale - Pas de Modification 4.0 International. 


\title{
Grigotá y Vitupue. En los albores de la historia chiriguana (1559-1564)
}

\author{
Isabelle Combès*
}

\section{Resumen}

Los chiriguanaes del piedemonte andino oriental en la actual Bolivia representaron una constante amenaza para la Audiencia de Charcas, y muchos indicios sugieren que lo fueron también para los incas. Sin embargo, al cruzar testimonios y crónicas quinientistas, aparecen «contradicciones» que obligan a replantear «los orígenes» del poder chiriguana en la Cordillera. Este artículo sugiere una toma de poder reciente, incluso colonial, por parte de estos grupos guaraníhablantes en la frontera oriental de Charcas.

Palabras clave: chiriguanaes, incas, chanés, frontera chiriguana, siglo XVI

\section{Grigotá et Vitupue. À l'aube de I'histoire chiriguana (1559-1564)}

\section{Résumé}

Les Chiriguanaes du piémont oriental andin de l'actuelle Bolivie représentèrent une constante menace pour l'Audience de Charcas, et de nombreux indices suggèrent qu'il en fut de même pour les Incas. Cependant, si l'on confronte les témoignages et les chroniques du XVIo siècle, des « contradictions » apparaissent, qui obligent à repenser « les origines » du pouvoir chiriguana sur la Cordillère. Cet article propose une prise de pouvoir récente, ou même coloniale, de ces groupes de langue guarani sur la frontière orientale de Charcas.

Mots clés : chiriguanaes, incas, chanés, frontière chiriguana, XVle siècle

\footnotetext{
* Instituto Francés de Estudios Andinos (UMIFRE 17, CNRS-MAE). E-mail: kunhati@gmail.com
} 


\title{
Gigotá and Vitupue. At the dawn of Chiriguana history (1559-1564)
}

\begin{abstract}
The Chiriguanas of the Andean foothills (Bolivia) were a constant threat to the Audiencia de Charcas, and several facts suggest that they were also a threat to the Incas themselves. Nevertheless, a critical comparison of XVIth century testimonies and chronicles reveals certain «contradictions» that allow to rethink «the origin» of Chiriguana domination. This paper argues for a recent - even colonialprocess of regional domination by the Guaraní speaking groups of the Eastern Charcas frontier.
\end{abstract}

Key words: Chiriguanas, Incas, Chanés, Chiriguana Frontier, XVIth century

¿Cómo pudo un puñado de guaraníes — guerreros y «abominables»— someter a miles de indígenas — «mansos»— del piedemonte andino? ¿Cómo conciliar la existencia de fortines incaicos en la «frontera chiriguana» con los escritos que atestiguan otro tipo de contactos, no necesariamente bélicos, entre chiriguanaes e incas? ¿Cómo se convirtieron en el flagelo de la Audiencia de Charcas los aliados de primera hora de los conquistadores españoles? Al cruzar testimonios y crónicas quinientistas, aparecen «contradicciones» y preguntas sin resolver acerca de «los inicios» del poder chiriguana en el piedemonte andino de Charcas. A estos temas está dedicado el presente artículo.

\section{LA AMENAZA CHIRIGUANA}

«Antropófagos y carniceros, ingratísimos y bestiales, viciosos y abominables, impíos, crueles y sediciosos, falsos y mentirosos, de poca constancia y lealtad» y, en suma, «amigos de la guerra y enemigos de la paz» (Díaz de Guzmán, 1979 [1617-1618]: 72), los indígenas chiriguanaes del piedemonte sur andino en la actual Bolivia representaron una constante amenaza para la Audiencia de Charcas, a tal punto que el mismo rey de España les declaró oficialmente la guerra en 1574. Todo parece mostrar que la amenaza chiriguana no era nueva y que los incas también la enfrentaron. Entre el río Guapay o Grande al norte y el Pilcomayo al sur, imponentes plazas fuertes incaicas como Pocona (Inkallajta) o Samaipata estaban flanqueadas por:

«... una densa red de fortines emplazados en sectores estratégicos (puertos, confluencia de valles), precedidos hacia abajo por puestos avanzados ubicados en la llanura del Chaco, que los españoles hallaron durante sus 
reconocimientos posteriores. Polo de Ondegardo los calcula precisamente en 44 y Díaz de Guzmán en unos 50. Estas fortificaciones testimonian a la vez la agudeza de la amenaza guaraní [chiriguana]» (Saignes, 2007: 48-49).

Las crónicas andinas hacen eco del peligro representado por «los chiriguanaes»y de las batallas libradas bajo el reino del inca Tupac Yupanqui según unos, o del de Huayna Capac según otros (Saignes, 2007: 47).

¿Quiénes eran estos chiriguanaes? Castellanizado en «chiriguano» a partir del siglo XVIII, el nombre designó en la época colonial (y buena parte de la República) a los actuales «guaraníes» del piedemonte andino sudoriental1. Pero su significación no siempre fue la misma. Los españoles del Paraguay, y luego de la primera ciudad de Santa Cruz fundada en la actual Chiquitania boliviana, no utilizaron este nombre hasta 1557, cuando aparece aparentemente por primera vez bajo la pluma de Jaime Rasquín (Rasquín, 2008 [c. 1557]: 43). En estos escritos, y hasta entrado el siglo XVII, «chiriguana» es un sinónimo de «guaraníhablante»; es así que los itatines o guarayos, e incluso grupos del río Paraná, también pudieron ser llamados «chiriguanaes». Más importante, las fuentes paraguayas son unánimes en señalar que el término viene «del Perú»:

«En la provincia del Perú los Ilaman chiliguanaes y en nuestra provincia [Paraguay] los llaman guaranis» (Rasquín, 2008 [c. 1557]: 43).

El significado del término parece haber sido diferente y en todo caso más amplio del lado andino: no pocos escritos hablan, por ejemplo, de la expedición de Diego de Almagro a «Chile o Chiriguana»2; mucho más al noreste, en la Amazonía hoy boliviana, un grupo de habla tacana fue llamado chirigua o chiriba (Brohan \& Herrera, 2008: 35). Todo parece indicar, entonces, que el primer sentido del término fue más bien genérico y que fue utilizado por los quechuahablantes para designar a «los salvajes» de ciertas regiones. En las palabras de Nordenskiöld:

«El significado de Chiriguano correspondió probablemente al de Chunchos en el distrito de Cusco, donde designaba a cualquier tribu bárbara del este de los Andes» (Nordenskiöld, 1920: XIII)3.

Esto significa, y el punto es importante, que no todos los «chiriguanaes» de las crónicas andinas corresponden a los «chiriguanos» guaraníhablantes del piedemonte andino. De hecho, son varios los autores que notaron que las expediciones incas a los «chiriguanas» descritas por Garcilaso de la Vega podrían más bien corresponder a incursiones hacia la Alta Amazonía o incluso hacia el Alto Paraguay (Garcilaso de la Vega, 1990 [1609], libro 7, cap. XVII; Saignes, 2007: 47; Langer, 2010).

1 Los «guaraníes» viven hoy en los departamentos de Santa Cruz, Chuquisaca y Tarija en Bolivia, y en el noroeste argentino.

2 Véase, por ejemplo, varios documentos reunidos por José Toribio Medina sobre la expedición de Almagro a Chile (Colección de documentos inéditos para la historia de Chile. Disponible en: http:// www.archive.org/detailscoleccindedocum03medigoog). Autores como Cieza de León, Herrera u Oviedo también hablan de «Chile o Chiriguana» (Langer, 2011).

3 Sobre los significados del término «chiriguana», remito a Combès (2010: artículo «Chiriguanaes») y a Langer (2011). 


\section{A LA DEVOCIÓN DEL INCA}

Al relatar los avances incas hacia las tierras bajas orientales, el mismo Garcilaso, lejos de hablar de batallas contra «los salvajes», indica que los incas ganaron «la amistad» de los musus (mojos):

«Dicen los Incas que cuando llegaron allí los suyos, por las muchas guerras que atrás habían tenido, llegaron ya pocos. Mas con todo eso se atrevieron a persuadir a los Musus se redujesen al servicio de su Inca, que era hijo del Sol, al cual había enviado su padre desde el cielo para que enseñase a los hombres a vivir como hombres y no como bestias [...] Viendo que los Musus les oían de buena gana, les dieron los Incas más larga noticia de sus leyes, fueros y costumbres [...] Con estas cosas se admiraron tanto los Musus, que holgaron de recibir la amistad de los Incas y de abrazar su idolatría, sus leyes y costumbres, porque les parecían buenas, y que prometían gobernarse por ellas y adorar al Sol por su principal Dios [...] Debajo de esta amistad dejaron los Musus a los Incas poblar en la tierra [...] y los Musus les dieron sus hijas por mujeres y holgaron con su parentesco» (Garcilaso de la Vega, 1990 [1609], libro 7, cap. XIV).

La nota de Garcilaso no es aislada. Otro texto de finales del siglo XVI relata de esta manera las estrategias incas para conquistar a los chunchos y mojos del este de los Andes:

«Lo que no podía por armas y guerra los traía así con sus mañas y embustes, dádivas y halagos. Porque pretendiendo conquistar las provincias de los chunchos y mojos por guerra, hicieron todo cuanto se pudo hacer y siempre salían perdidosos, porque las tierras de arcabucos y montañas son cálidas y enfermas para gente serrana y de tierra fría, y los mantenimientos muy diferentes de los de la serranía [...] Visto por los Incas el poco remedio que tenían para gente de montañas, trabajaron de traerlos a su amistad mañosamente, como se ha referido atrás, con dádivas y halagos; así conquistaban toda tierra de montañas y dificultosa. De la suerte que se ha dicho, conquistaron los Incas y señorearon todas las provincias de los chunchos, mojos y andes» (Discurso..., 1906 [s/ff]: 155-156).

De la misma manera, esta vez en la región del río Guapay, la Relación Cierta del padre Diego Felipe de Alcaya cuenta cómo Guacane, inca de Samaipata, atrajo al jefe Grigotá a su obediencia:

«Llevó gran suma de preseas de vestidos de cumbi, cocos y medias lunas de plata, y escoplos y hachuelas de cobre, para presentar al gran cacique Grigota y a sus vasallos con fin de traerlos a su devoción [...] Y luego despachó a un su [sic] capitán con un presente de muy lúcidos vestidos de cumbi triplicados para que se mudase y en que hubiese cocos de plata de diferentes hechuras, el cual fue muy bien recibido de Grigota. Y fue a dar el bien venido al nuevo rey Guacane con muchos indios desnudos, y él salio con sola una camiseta variada de colores hecha en su tierra de algodón, y luego que se vieron 
quedaron confirmadas las amistades, de manera que se despojó de todo punto de su señorío y mandó y le dio el reconocimiento de vasallo, él el primero y luego todos sus pueblos. Allí se juntaron los caciques Goligoli, Tendi, y Vitupue, todos principales que estaban sujetos al gran Grigota, y con sus parcialidades que pusieron de 50.000 indios dieron la obediencia al nuevo rey Guacane» (AGI Charcas 21 r. 1 N. 11, bloque 7 (1636): 1v-2).

Confrontadas con los relatos de las cruentas guerras contra los indígenas de las tierras bajas, estas notas muestran la existencia de otros medios, más pacíficos y basados en el trueque o la alianza, para asegurar el avance inca hacia el este entre chunchos, musus o antis. ¿Habrán sido los fuertes, pucaras y demás dispositivos bélicos destinados exclusivamente para los «chiriguanaes»? Pues nada parece menos seguro, y el mismo Garcilaso, de nuevo, aporta una nota discordante. Si bien, según él, el Inca se desinteresó de su conquista y se retiró, algunos contactos sí habrían tenido lugar; lo importante es que no fueron del todo hostiles:

«De la poca conversación y doctrina que de la jornada pasada de los Incas pudieron haber los Chirihuanas, perdieron parte de su inhumanidad, porque se sabe que desde entonces no comen a sus difuntos como solían [...] También aprendieron los Chirihuanas de los Incas a hacer casas para su morada» (Garcilaso de la Vega, 1990 [1609], libro 7, cap. XVII).

Más aún, Rui Díaz de Guzmán relata que, cuando llegaron los guaraníes desde el Paraguay «a esta frontera donde el señor Inca del Perú tenía más de 50 fuertes»:

«... llegados los dichos guaranís a esta provincia muy destrozados y perdidos del trabajo del camino y de los encuentros y peleas que con diversas naciones tuvieron, se mostraron humildes, sometiéndose a la servidumbre de dicho inca» (Díaz de Guzmán, 1979 [1617-1618]: 72; el subrayado es mío).

Y si bien los chiriguanaes luego «tomaron fuerzas y ánimo» para atacar a los incas, ambas observaciones de Garcilaso y de Díaz de Guzmán muestran que las relaciones no se redujeron a enfrentamientos armados y que tuvieron otros matices. En palabras de Saignes, el relato de Díaz de Guzmán muestra «que las incursiones paraguayas no cobraron tantos triunfos como reporta la crónica» (Saignes, 2007: 50).

Lo mismo puede decirse de los contactos entre los guaraníes establecidos en el piedemonte con los españoles. Pues no siempre los chiriguanaes fueron tan «abominables» como los pintó Díaz de Guzmán. A la llegada de los primeros conquistadores a la zona (Andrés Manso en 1559, desde Charcas, y Ñuflo de Chávez en las mismas fechas, desde Asunción), los chiriguanaes actúan, si no como reales «amigos», al menos como aliados e «indios de paz». Es solo pocos años después, en 1564, cuando los asaltos chiriguanaes a las nuevas fundaciones de la Nueva Rioja y La Barranca abren las hostilidades que desembocarán sobre la guerra declarada por Felipe II y no cesarán durante toda la Colonia.

La confrontación de diversos testimonios y de estas fechas plantea, por decirlo así, el problema del «origen» del poder chiriguana. Lo hace también otra «contradicción» poco o nada estudiada hasta ahora, que es la que motivó este 
artículo4: pues en los años 1580, varios testimonios muestran a los indígenas tamacoci del río Guapay como tributarios, o incluso esclavos, de los chiriguanaes de «la provincia de Vitupue», que era el nombre del máximo jefe chiriguana de la región. En 1584, el gobernador de Santa Cruz, Lorenzo Suárez de Figueroa, alcanza en camino a:

«... diez indios tomacozies, con guacamayas y sus arcos y flechas, algunas de yerbas [ponzoñosas], que iban a los chiriguanaes a darles su tributo y a servirles» (AGI Pat. 235 r. 8: 23r; Mujía, 1914, t. 2: 410).

Un año después, otro testimonio describe los tributos entregados por los tamacoci: «indios e indias, arcos y flechas y pescado y caza y guacamayas»5. Los tamacoci no son los únicos tributarios de los chiriguanaes (sus vecinos jores y yuracares entregan a su vez flechas y otros objetos) y, de hecho, estos testimonios corresponden con todos los de esta época, que muestran a los chiriguanaes esclavizando o al menos dominando fuertemente a los «naturales de los llanos». Y sin embargo, para la época inmediatamente prehispánica, la Relación Cierta de Alcaya, ya citada, muestra a Grigotá, jefe tamacoci, rodeado de vasallos; uno de ellos se llama Vitupue.

\section{LOS CHIRIGUANAES DE TOLEDO}

Sin haber salido de España todavía, el virrey del Perú, Francisco de Toledo, recibió en 1568 una orden real para emprender la guerra contra los chiriguanaes del piedemonte andino (BN Madrid 3044: f. 309; véase Julien,1997). Una vez en su puesto, el Virrey reunió en dos ocasiones testimonios y «pareceres» autorizados para preparar la guerra: en Cusco y Yucay en 1571, y en Charcas en 15736. A decir verdad, se trataba sobre todo de justificar una guerra ya decidida; los testimonios son unánimes para declarar que, en efecto, «la guerra es justa» y «el dicho castigo es lícito» (Mujía, 1914, t. 2: 219, 221). Las razones alegadas son básicamente las siguientes.

En primer lugar, los chiriguanaes no son oriundos de «la Cordillera» donde moran, son «advenedizos», «vinieron allí del río de La Plata» (Lizárraga, 1968 [c. 1600]: 83); «la cepa de ellos [...] es en el río de La Plata», desde donde llegaron a «conquistar y traer a sujeción la gente en cuya comarca residen» (Polo de Ondegardo, 1914 [1574]: 83). Más tarde, Suárez de Figueroa lo confirma:

4 Esta contradicción fue expuesta ya, sin resolverla, en Combès (2010: artículos Grigotá, Vitupue, Goligoli y Tendi).

5 Blas (1914 [1585]: 684); véase también la Información de servicios de Gonzalo Solís de Holguín (1914 [1603]: 72)

6 Los testimonios levantados en 1571 se encuentran en AGI Pat. 235 r. 1, fueron publicados por Mujía (1914, t. 2: 53-82) y recientemente por Julien bajo el título «Información de los chiriguanaes» (2008). Esta última edición es la que utilizo aquí. Los testimonios recogidos en Charcas, en 1573, son pareceres de oidores de la Audiencia de Charcas como Polo de Ondegardo, Matienzo, etc. Fueron publicados por Mujía (1914, t. 2: 82-98, 218-252) y Levillier (1922, t. 1: 271-298). 
«Su origen y principio dicen que es de la costa del Brasil y han ido extendiéndose por muchas partes e provincias, poblando donde hay mucha gente, para ejecutar su crueldad natural contra el género humano» (Suárez de Figueroa, 1965 [1586]: 404).

En tanto que dueños ilegítimos de estas tierras - pueden ser expulsados y combatidos - el argumento es, de paso, exactamente el mismo que el que el mismo Toledo esgrimió para justificar su lucha sin tregua contra los últimos incas (Julien, 1997).

En segundo lugar los chiriguanaes son, además de «brutos hombres, comegentes» (Lizárraga, 1968 [c. 1600]: 144), caníbales y comer carne humana es su «principal costumbre y felicidad», su «principal manjar» (Información de los chiriguanaes, 2008 [1571]: 225-226). Ejercen esta crueldad contra los indios «mansos» de los Ilanos (los más frecuentemente mencionados son los chanés), algunos de los cuales, como los chichas sureños, ya son vasallos de Su Majestad:

«Hacen tributar a los indios de los Ilanos de Manso o Condorillo que están cerca de allí y les hacen dar y tributar ropa e hijos e hijas y a los que esto no quieren hacer los comen y hacen otros muchos daños. Y estos mismos daños hacen a los indios de los repartimientos de Santa Cruz [...] les hacen la guerra y a los que toman, que son los que ellos quieren por ser la gente doméstica, se los comen y tienen por esclavos para criarles sus hijos y otros servicios» (Información de los chiriguanaes, 2008 [1571]: 224-225, 230).

El papel del Virrey es, evidentemente, defender a estas víctimas y, de hecho, las instrucciones dadas por Toledo al nuevo gobernador de Santa Cruz, en 1571, le intiman ofrecer «amparo y defensa» a los indios de los Ilanos contra los chiriguanaes (Toledo, 1914 [1571]: 23).

La guerra iniciada por Toledo, y de la cual participó en persona en 1574, fue un total fracaso para los españoles; por poco no falleció el Virrey en los meandros de la Cordillera chiriguana:

«Salió el Visorrey huyendo, y desamparó todo lo que llevaba, para que los indios se contentasen con presa que les dejaba y lo dejasen a él. Salió por tan malos caminos, que, por no poder llevar las acémilas una literilla en que caminaba, la sacaron en hombros indios y españoles; y los Chirihuanas que los seguían, dándoles grita, entre otros vituperios les decían: 〈Soltad esa vieja que lleváis en esa petaca (que es canasta cerrada), que aquí nos la comeremos viva»» (Garcilaso de la Vega, 1990 [1609], libro 7, cap. XVII).

Tuvieron mucho que ver, en el fracaso del Virrey, los mestizos que habitaban en la cordillera chiriguana y los que vivían en Santa Cruz, en probable colusión con los chiriguanaes (Combès, 2009); sin embargo, más allá de esta situación puntual, esta guerra fracasó por las mismas razones que hicieron fracasar todas las tentativas posteriores por reducir los chiriguanaes: los españoles no se adaptaban a la guerra chiriguana y, sobre todo, no lograban entender su sistema político. Felipe II declaró la guerra a una «nación», y nada podía estar más alejado de la 
realidad. Los chiriguanaes tenían tantas cabezas como «provincias» (en términos coloniales) o «capitanías» y más aún, pues cada una de las aldeas que integraba una capitanía tenía su propio cacique. En tiempos de guerra, varias de estas provincias podían aliarse contra un enemigo común, pero para retomar luego un incesante ciclo de guerras y rivalidades internas; así, en no pocas ocasiones, algunas se aliaron incluso con los españoles para poder luchar contra sus vecinos — renegando de esta alianza una vez alcanzado el objetivo 7 - En los tiempos de Toledo, las principales «provincias chiriguanaes» entre el Guapay y el Parapetí eran, por un lado, las de Vitupue, cuya «capital» se ubicaba sobre el río Grande «en aquella parte que este río deja las sierras y comienza a llevar sus corrientes por los llanos» (cerca del actual pueblo de Abapó entonces), a unas doce leguas de Samaipata (Relación Verdadera, 2008 [1571]: 213; AGI Pat. 235 r. 8; Mujía, 1914, t. 2: 422); y por otro lado la de Condorillo, con los jefes Amaru Care o Marucare, en la zona del Parapetí más hacia el sur. Con muchos otros de sus «subordinados», estos tres caciques figuran en la lista de los jefes chiriguanaes que quiso agasajar Toledo en 1573 (Toledo, 2008 [1573]; Lizárraga, 1968 [c. 1600]: 144).

En un ensayo de 1997, Catherine Julien habla de una «demonización» de los chiriguanaes por parte de Toledo y sus acólitos, con el objetivo de justificar la guerra de conquista al este de Charcas. Esta demonización por cierto fue real: el hecho no impide que los argumentos del Virrey descansasen sobre bases concretas, ni que los chiriguanaes hayan representado realmente, cuando se les declaró la guerra, un apremiante peligro tanto para los españoles como para los indígenas de los llanos.

\section{4. «LA UNIÓN DE SUS CASAMIENTOS»}

Sobre la condición de «advenedizos» de los chiriguanaes (que los toledanos equipararon a la de «usurpadores»), mucho se ha escrito desde un célebre artículo de Erland Nordenskiöld (1917), Alfred Métraux (1927; 1930) y Enrique de Gandia (1929; 1935), en particular, dedicaron sendas páginas a las migraciones guaraníes hacia el Occidente; hasta un reciente «estado de la cuestión» sobre este tema (Combès, 2011). Contrariamente a lo que sugiere el título escogido por Nordenskiöld, la llegada de grupos guaraníhablantes hasta el piedemonte no puede ser vista como una «invasión», y mucho menos considerarse como un acontecimiento único y puntual. Fueron varias olas de migraciones y lentas llegadas en un proceso paulatino que se extendió, con seguridad, durante varios siglos. Un estudio arqueológico reciente sugiere incluso una fecha tan temprana como 400 d. C. para la presencia guaraní en la cordillera chiriguana (Pärssinen, 2003). Poco o nada es lo que sabemos sobre migraciones tan antiguas y desconocemos, en particular, su magnitud y sus alcances. Lo que sí parece establecido es que el

7 Un ejemplo paradigmático de este proceso fue analizado por Saignes (2007). Es la historia de la campaña militar de Rui Díaz de Guzmán entre los chiriguanaes, utilizado y manipulado por nada menos que tres capitanías chiriguanaes rivales. 
flujo de migrantes se incrementó muy poco antes de la llegada de los primeros españoles, debido probablemente a la atracción ejercida por los centros inca de Samaipata y Saypurú. A título indicativo, la Relación Cierta de Alcaya indica una cifra de 8000 guaraníes llegados en tiempos del inca Huayna Capac: 5000 de ellos se habrían quedado en el piedemonte (AGl Charcas 21 r. 1 N. 11: 3). Tampoco pueden olvidarse — volveré sobre este punto más adelante—las migraciones más recientes de varios miles de guaraníes que acompañaron a los conquistadores del río de La Plata: Alejo García en los años 15308, Domingo de Irala en 1548 y Ñuflo de Chaves en 1557 y nuevamente en 1564.

Al llegar al piedemonte, los recién llegados habrían empezado a dominar a los indígenas de la zona, chanés de lengua arawak en su mayoría, convirtiéndolos en esclavos, tributarios o víctimas del rito caníbal. Esta era, en todo caso, la situación general que se conocía en la segunda mitad del siglo XVI. Muchos cronistas indican además que los chiriguanaes enrolaron a estos «naturales» en sus propias tropas: «a los indios que cautivan los engordan para comer, si no es al que hacen chiriguanaes para ayudarse de él» (Información de los chiriguanaes, 2008 [1571]: 230); «también les industrian en pelear» (Polo de Ondegardo, 1914 [1574]: 83); «de los que ven valientes y de buenos cuerpos se aprovechan para la guerra; los hacen a sus bárbaras costumbres y cuando han de pelear los ponen por las espaldas» (Lizárraga, 1968 [c. 1600]: 84).

Los mismos cronistas subrayan, unánimes, que los guerreros guaraníes desposaron a las cautivas de guerra «con que vinieron en gran multiplicación» (Díaz de Guzmán, 1979 [1617-1618]: 73): «la mayor parte son mestizos hijos de indias de los llanos e indios que con la compañía se han enseñado a pelear y lo hacen tan bien como los chiriguanaes que también les han dado sus hijas y están revueltos» (Polo de Ondegardo, 1914 [1574]: 87); los chiriguanaes están «envueltos con mil gentes diferentes» (Barco Centenera, 1969 [1602], canto I); «les llaman chiriguanaes, corrompido el vocablo, el cual se deriva de chiriones, que quiere decir «mestizos, hijos de ellos y de indias de otras naciones»» (Suárez de Figueroa, 1965 [1586]: 405). Un paulatino mestizaje acompaña en efecto a la dominación, un mestizaje de tanta amplitud que pudo ser calificado de pilar de la «identidad chiriguana» (Combès \& Saignes, 1991). Las cifras disponibles para la época colonial temprana muestran que «los chanes que tienen por esclavos (...) son muchos en comparación de los pocos que ellos son» (Diego de Contreras, ADI Montesclaros t. 5 doc. 72: 3v). Lizárraga menciona la escalofriante cifra de 60000 chanés de los llanos devorados por los chiriguanaes (Lizárraga: 1968 [c. 1600]: 83-84). En 1618, Arce de Almendria calcula un número de 950 a 1500 «chiriguanaes», y una cifra diez veces superior de chanés (AGI Lima 38); lo mismo hacía poco antes Diego de Contreras, Ilegando incluso, en casos como el de Macharetí, a indicar 30 chiriguanaes por 800 chanés en un solo pueblo9. Recién a finales del siglo XVIII la proporción se invierte y los

8 Las fechas del viaje de Alejo García fueron recientemente establecidas por Julien (2005).

9 Diego de Contreras, ADI Montesclaros t. 5 doc. 72: 8v-10v. Otras estimaciones demográficas en Combès \& Saignes (1991: 58-59). 
chanés «son menos en el número» que los chiriguanaes (Mingo de la Concepción, 1981 [1791]: 117): el mestizaje entre guaraníes y chanés ya está prácticamente consumado, y con él la guaranización (lingüística en particular) de los segundos por los primeros. Hoy, el único grupo que todavía se denomina «chané» en el norte argentino es guaranihablante.

A pesar de una relación demográfica muy desfavorable a los guaraníes, se puede entender que el idioma guaraní se haya impuesto a lo largo de los años, pues los «naturales» de los Ilanos eran muchos, de diferentes etnias y lenguas. Si bien los chanés de lengua arawak predominaban, tenemos también referencias de unos misteriosos «comiches» y otros «copores», de los cuales sabemos que tenían idiomas diferentes; de los «timbus» de la región de Santa Cruz, río Grande abajo; de los matacos al sur y de los chichas de la región tarijeña; todos diferentes y víctimas de los chiriguanaes10. Único idioma común, el guaraní pudo haber sido utilizado primero como lengua franca, para luego afirmarse como lengua general.

Es más difícil entender, en términos demográficos, cómo un puñado de gente (aun animados por una «canina rabia» [Barco Centenera, 1969 [1602]: 5r]) pudo dominar a tantos indígenas (aun «mansos» y sumisos11). De nuevo aflora la cuestión, ya planteada en el primer acápite, de «los orígenes» de la dominación chiriguana, esta vez sobre los indígenas llaneros. A decir verdad, una primera respuesta ya fue dada a esta pregunta, comparando la relación entre chiriguanas y chanés con la que unía a mbayá-guaykurú y chanés al este del Chaco boreal. Existen testimonios muy tempranos sobre la esclavitud de los chanés (más tarde llamados también guanás) chaqueños en manos de los mbayá-guaykurú (Schmidel, 2008 [1567], cap. 44). En el siglo XVIII, el padre jesuita Sánchez Labrador explicaba de esta manera esta sujeción. Los mbayá:

«... emparentaron con los infieles guanás, a los cuales ellos llaman Niyololas, y al presente les sirven como feudatarios. No hemos podido averiguar que los conquistaron por armas, sino por la unión de sus casamientos. Algunos caciques o caciques Eyiguayeguis [mbayá] se casaron a su modo con cacicas o capitanes guanás. Los vasallos de éstas, muertas ellas, quedaron en un perpetuo feudo a los descendientes de los maridos de sus señoras» (Sánchez Labrador, 1910 [c. 1770], t. 1: 267).

En la perspectiva que ofrece Sánchez Labrador, los mbayá se habrían adueñado así de la estricta jerarquía sociopolítica chané, desposando a las mujeres «nobles» imbuidas de la «mística nobleza de su sangre» (Sánchez Labrador, 1910 [c. 1770], t. 1: 26). La misma jerarquía entre «Casas» nobles y plebe, el mismo sistema político hereditario, se vuelven a encontrar entre los chanés occidentales mestizados, a

10 Sobre los copores y comiches, véase Manso (2008 [1563]); sobre los timbú, véase Combès (2010: 287-288).

11 Los testimonios son elocuentes al respecto. Los chanés son «la gente más doméstica que nunca se vio» (Polo de Ondegardo, 1914 [1574]: 86); «son tan bestiales y brutos que sin resistencia se les rinden y dejan llevar por esclavos» (Carta del lic. Cepeda a Su Majestad, 1595, en Levillier [1922, t. 3: 262]); los chiriguanaes les llevan «como ovejas en manada» (Lizárraga, 1968 [c. 1600]: 84), etc. 
su vez, con los guaraníes; de ahí la hipótesis, en el piedemonte andino, de un proceso similar al que fortaleció a los mbayá del Chaco (Combès \& Villar, 2004; Combès, 2005; Combès \& Lowrey, 2006).

Esta hipótesis nos sigue pareciendo sólida y válida, aunque tal vez no suficiente. La conquista «por parentesco» de los chanés orientales por los mbayá no estuvo acompañada de violencia, al menos hasta finales del siglo XVIII cuando este sistema interétnico empezó a quebrantarse (Richard, 2008). En el piedemonte, por el contrario, los matrimonios interétnicos no impiden la violencia - guerra, canibalismo, venta de esclavos- de los chiriguanaes hacia los chanés y demás «naturales de los llanos». Tal vez puedan proponerse, entonces, otros elementos para explicar o entender mejor la dominación de los chiriguanaes sobre los chanés y, de manera más general, su innegable poder sobre toda la Cordillera en la época colonial. Propongo explorar aquí algunas de las versiones coloniales sobre el tema; son tanto más interesantes, variantes más, variantes menos, que hacen intervenir en este proceso a otros actores: los incas por un lado y los españoles por otro. Por si fuera poco, una de ellas propone para la época prehispánica un cuadro totalmente imprevisto y radicalmente opuesto a la situación general reinante en la segunda mitad del siglo XVI: un jefe tamacoci de los llanos, al mando de vasallos chiriguanaes.

\section{GRIGOTÁ Y VITUPUE}

Una primera información nos es provista por Domingo de Irala cuando, en 1543, remonta el río Paraguay desde Asunción y encuentra en una laguna del pantanal (probablemente la actual laguna La Gaiba) a varios chanés que le hablan en guaraní, y le nombran al portugués García que había pasado por estas tierras pocos años antes:

«Preguntado que cómo hablaba guaraní y dónde conoció al dicho García, dijo que la causa porque hablaba guaraní era que en tiempos pasados, antes que García viniese del Brasil a los dichos guaraníes, se hizo una gran junta de los dichos guaraníes en el puerto que llaman de Ytatin [sobre el río Paraguay] para ir a buscar el metal y que, pasando por su tierra de ellos de noche dieron en sus casas y mataron muchos de los suyos y prendieron a sus mujeres e hijos, y a ellos los trajeron al dicho puerto de Ytaytyn; y que estando ellos en el dicho puerto por esclavos de los dichos guaraníes, pasó por allí el dicho García, con el cual él y otros dos hermanos fueron en busca del dicho metal con los dichos guaraníes» (Irala, 2008 [1543]: 7-8).

Según este relato, la esclavitud y la consiguiente guaranización de los chanés tendrían sus orígenes en las migraciones guaraníes (prehispánicas en este caso) hacia el oeste, en busca del metal andino.

Otros relatos son mucho más detallados, como es el caso de la Relación Cierta del padre Alcaya. La versión que conocemos de este texto se remonta a 1636; sin embargo, la mayor parte de su contenido se basa sobre otra relación más antigua, 
dejada por Martín Sánchez de Alcayaga, padre del cronista y conocido poblador de la primera ciudad de Santa Cruz12. La Relación Cierta cuenta en realidad dos historias paralelas. Por un lado, la del Inca Manco poblando el Paititi en algún lugar de la Amazonía; y por otro lado, la de los dos incas hermanos, Guacane y Condori, en Samaipata y Saypurú —es decir, en la cordillera chiriguana_. Esta última es la que nos interesa aquí. Pariente del Inca del Cusco, Guacane partió al este y se instaló en «Sabaypata». Como ya se mencionó, logró «traer a su devoción» a los indígenas de los llanos cercanos, obteniendo en particular la obediencia del jefe Grigotá y sus vasallos: Goligoli, Tendi y Vitupue. Según Alcaya, «Grigotá» no sería un nombre sino un título:

«Así se llamaban todos los que [se] sucedían en el gobierno, como en Roma los Césares, los faraones en Egipto y los incas en el Cuzco» (AGl Charcas r. 1 N. 11: 1).

De esta manera, el Inca del Cusco despachó a Condori, hermano de Guacane, con 5000 hombres a la región. Condori empezó a trabajar, más al sur en la cordillera, la mina de Saypurú.

Es entonces que, atraídos por la fama de riqueza de los dos incas, los guaraníes del Paraguay, acompañados por otros grupos como los xarayes del Pantanal, decidieron apoderarse de ellas. Eso ocurría, dice Alcaya, once años antes del viaje de Juan de Ayolas desde el Paraguay hasta el Occidente — vale decir, en 1526—. De 8000 guaraníes que salieron, «5 000 de ellos vinieron para Grigota»:

«Y allí se detuvieron un invierno, desde donde enviaban sus espías a los llanos de Grigota, donde el rey Guacane sin ningún cuidado se holgaba con los suyos como en su reino. Y mientras el invierno hacía su curso, esta carnicera nación se ocupaba en hacer grandes matanzas en estos desnudos naturales, comiendo criaturas y gozando de sus mujeres como de las suyas propias, a fin de levantar y engrandecer su nombre por toda la tierra y castigar con su cruda condición a los naturales y comarcanos» (AGI Charcas r. 1 N. 11: 3v).

En un primer ataque guaraní, Guacane encontró la muerte y «Grigota salió mal herido aunque no murió. Se escaparon muchos indios y mujeres». En represalia, el Inca del Cusco despachó al capitán Turumayo contra los guaraníes, que también acabó siendo vencido por ellos. De nuevo, por esta batalla, «se escaparon muchos indios de este reino y de los llanos»». Instalados los guaraníes en la comarca, empezaron a adueñarse de ella y de sus habitantes:

«El cacique Grigota y los demás de la comarca recibían cada mes notables daños en sus pueblos y chozas donde se habían retirado, cautivándoles sus mujeres e hijos estos extranjeros enemigos, los aborrecían grandemente» (AGl Charcas r. 1 N. 11: 4r-v, 5).

Es entonces que Grigotá decide contraatacar solo, esta vez con éxito. Ahí se ubica un episodio célebre de la gesta contada por Alcaya, cuando Grigotá manda a

12 Un análisis de la Relación Cierta de Alcaya(ga) en Meyers \& Combès (2011). 
200 chiriguanaes prisioneros al Inca del Cusco, y este los castiga exponiéndolos desnudos al frío en lo alto de un cerro nevado.

La crónica nada dice sobre los acontecimientos que siguen, y recién retoma el hilo en 1548 (fecha que podemos establecer por las crónicas paraguayas que relatan el viaje de los asuncenos a través del Chaco), cuando Domingo de Irala, gobernador de Asunción, «se dispuso al nuevo descubrimiento de los llanos de Condori y Moxos. Y vino por el [mismo] viaje que los guarinis, y llegó a los llanos de Grigotta con 350 hombres». Grigotá lo recibe bien, «muy gozoso vino con buenos presentes de la tierra y sus caciques y muchos indios, y dieron la paz al capitán Irala con fin de confederarse con él para desterrar de sus pueblos y tierras a los chiriguanaes» (AGl Charcas r. 1 N. 11: 9).

Sin embargo, en busca de minas y metales, Irala logra entrevistarse con Condori, el inca de Saypurú que quedó prisionero de los chiriguanaes. Este, bien aleccionado, le revela que los metales tan buscados son los de las minas de Charcas, ya en poder de los españoles del Perú, tras lo cual vuelve Irala a Paraguay, librando Grigotá a su suerte. En este punto termina la crónica. El relato de Pero López ofrece posteriores noticias de Grigotá: indica que fue preso por el conquistado Andrés Manso, llegado a «Quiricota» en 1559 desde Charcas, pero que aceptó luego servir al español. Grigotá habría juntado en esta ocasión unas 10000 personas entre hombres y mujeres para dar su amistad a Manso (López, 1971 [c. 1570]: 86)13. Sin embargo, si el nombre fue realmente un título como lo indica Alcaya, no tenemos la seguridad de que se tratase del mismo personaje.

Los documentos paraguayos que relatan el viaje de Irala a través del Chaco en 1547-1548 y su llegada a los Ilanos del río Guapay no mencionan a Grigotá, pero sí se refieren a un encuentro con los indígenas tamacoci. De hecho, la «provincia de los tamacoci» es el equivalente de la «provincia de Grigosta» en los escritos de la época, y podemos afirmar con seguridad que Grigotá era el cacique de este grupo. Varios estudios muestran también, como ya lo sugerían Sanabria y Saignes por ejemplo, que los tamacoci eran, con mucha probabilidad, un grupo chané de habla arawak14. En todo caso, como se ha visto, los tamacoci eran en los años 1580 tributarios de los chiriguanaes, al igual que los chanés y demás «naturales de los llanos».

De ahí el problema planteado por la mención de sus tres vasallos en la época prehispánica: Goligoli, Tendi y Vitupue. Pues Vitupue aparece a partir de 1560 como uno de los máximos jefes chiriguanaes de la Cordillera, «el más poderoso de estos chiriguanaes» (Polo de Ondegardo, 1914 [1574]: 95) y la «provincia de Vitupue» no es otra que la también Ilamada «provincia de Grigotá»15. Esta «provincia» reunía en 1584 a varias aldeas chiriguanaes que tenían sus propios caciques pero a la vez reconocían la autoridad general de Vitupue:

13 «Quiricota» citado en Sánchez (1906 [s/f]: 40).

14 Remito sobre estos temas a Combès \& Hirtzel (2007), y Combès (2010: artículos Grigotá y Tamacoci).

15 «Los llanos de girigota en la prouincia de Vitupue» (Ozores de Ulloa, 1587), BN Madrid ms. 3044. 
- Ytacuiran y Caracara, con los caciques Curipuy [Caripui], Corembu y Morecapy.

- Guapea o Aguapea, con los caciques Guapea, Naipu (o Naipeci) y Caybe.

- Tambora, cuyos caciques eran Vitupue mismo y Yaparo, Sabayuque y Eyra.

- Tendi, con el cacique Yabagu, hijo de Tendi, y otros dos llamados Neca y Cuyuru.

- Coyagua, con los caciques Coyagua y Taruyu. Coyagua estaba ubicada a 9 leguas de Samaipata, probablemente río Grande, un poco más arriba de Tambora o más al norte (AGI Pat. 235 r. 8: 28; Mujía, 1914, t. 2: 416-417, 422).

Otros caciques conocidos al mando de Vitupue eran Matarapa y Amboa (Testimonio y relación..., 2008 [1561]: 116; Relación de los servicios de Ñuflo de Chaves y Álvaro de Chaves, 2008 [1588]: 259).

Tendi, nombre de otro vasallo de Grigotá, aparece entonces como el de un cacique chiriguana. Sabemos que, como tal, poseía «esclavos» entre los indígenas de los llanos, por ejemplo los habitantes del pueblo de Guatuco (AGI Pat. 235 r. 8: 28v; Mujía, 1914, t. 2: 417).

La seguridad no es la misma en cuanto a Goligoli. Según Sanabria, «consejas populares antiguas entre los campesinos de Vallegrande mencionan a cierto Goligoli, bravo guerrero indígena y dueño de opulentos tesoros» (Sanabria, 1949: 33). El mismo autor dice que en 1602 el nombre de Goligoli vuelve a aparecer en las cercanías del Guapay, «como asignado a un paraje en el cual tenía una corta hacienda de ganado el residenciado Juan de Montenegro» (Sanabria, 1961: 72). El nombre de Goligoli aparece también en 1561 en el padrón de encomiendas y otros documentos relativos a la primera ciudad de Santa Cruz, fundada a unos 300 km al este del Guapay. Se menciona a «los xarionos, que por otro nombre se dice los goligolis» (Repartimiento, 2008 [1561]: 104; Testimonio y Relación..., 2008 [1561]: 115); en otros documentos, los «xarionos» se transforman en xerionos o xarronos (Testimonio y Relación..., 2008 [1561]: 115; Información de servicios de Ñuflo de Chaves, 2008 [1561]: 78). Se sugirió anteriormente que este nombre podría ser equiparado al de «cheriones», siendo este último término un nombre dado a los mismos chiriguanaes; por lo tanto, el mismo Goligoli habría podido ser chiriguana al igual que sus colegas Tendi y Vitupue (Combès, 2010: artículo Goligoli)16. Otra hipótesis es posible, pues el sufijo -ono presente en el nombre de los xarionos es un plural arawak (chané). Goligoli no es el único nombre registrado en el Guapay que vuelve a aparecer en Santa Cruz: en el mismo caso están por ejemplo los dos caciques Tomacoçi y Tamagoci (Repartimiento, 2008 [1561]: 101, 109), cuyos nombres evocan evidentemente a los tamacoci del Guapay. ¿Podrían estos nombres atestiguar las huidas de los «naturales» mencionadas por Alcaya para escapar del furor chiriguana?

En todo caso, y dejando en suspenso el caso de Goligoli, el problema sigue en pie en cuanto a Tendi y Vitupue, caciques chiriguanaes en los años 1560-1580 y amos de

16 Es en todo caso incomprensible la nota de Susnik (1978: 49), quien afirma que Goligoli sería la pronunciación chiriguana de «Grigotá» pues ambos personajes son nombrados al mismo tiempo, en el mismo documento, uno siendo vasallo del otro. 
la Cordillera, y poco antes vasallos de un jefe tamacoci17. Sin poder ser totalmente descartado, un error de Alcaya es improbable en este caso, inexplicable por parte de un cronista originario de la provincia de Santa Cruz, donde todos conocían la figura del Vitupue chiriguana. Lo curioso es que la «contradicción» planteada por Alcaya no fue prácticamente notada por los investigadores. Sanabria (1949) se contenta con decir que los nombres de Tendi y Vitupue están registrados luego en los documentos, pero no lo plantea como un enigma. Branislava Susnik sí nota la contradicción y la resuelve proponiendo lo siguiente: Vitupue y Tendi serían los nombres de caciques «grigotanos» (los vasallos mencionados por Alcaya) vencidos por los chiriguanaes, que habrían adoptado sus nombres (Susnik, 1968: 98). De hecho, ejemplos de esta práctica existen: los caciques chiriguanaes Pero (Pedro) y Chaues (Chaves) de la misma época sacan sus nombres de españoles (Combès, 2010: 124, 240); el nombre del chiriguana Condorillo (o incluso inca Condorillo) del río Parapetí remite, evidentemente, al inca Condori de Saypurú vencido por los guaraníes, etc. El problema es que Vitupue al menos parece ser un nombre genuinamente guaraní —algo como Ivitu pua, «el viento que se levanta»—: «lbitupuá, viento levantado», en palabras de Barco Centenera (1969 [1602]: 121). Asumamos entonces, a título de hipótesis, que Alcaya estuvo en lo cierto al escribir su crónica. De hecho, puede compararse su relato con el, ya mencionado, de Díaz de Guzmán. Según él, en efecto, los guaraníes migrantes, llegando «muy destrozados» a la frontera inca, «se mostraron humildes, sometiéndose a la servidumbre del dicho inca» — eso correspondería a la obediencia rendida por Grigotá y sus vasallos chiriguanaes a Guacane-.

\section{6. «SE COMÍAN TODAS LAS FRONTERAS»}

Se trate de la corta mención de Irala, de la larga historia de Alcaya o de la versión de Díaz de Guzmán, los escritos de la época relacionan directamente el inicio de la esclavitud o del sometimiento de los chanés — o, de forma general, de los «naturales»- con un impacto inmediato de las migraciones guaraníes. Las crónicas mencionan varias de estas migraciones: «antes que García viniese» (en la época prehispánica entonces); otra acompañando al mismo García; otra posterior a él, pero que implicó solamente la actuación de indígenas sin intervención de europeos, etc. De hecho, como se ha visto, si bien la lista de siete migraciones establecida por Gandia (1929; 1935: 29) parece demasiado perfecta para ser cierta, lo cierto es que podemos hablar de varias oleadas migratorias de los guaraníes al piedemonte, algunas de ellas bastante antiguas según las hipótesis arqueológicas.

17 Existe una diferencia de fechas entre la mención del Vitupue prehispánico (c. 1526) y la del jefe chiriguana (a partir de 1560); de la misma manera, el Tendi chiriguana aparece en las fuentes a partir de los años 1585. Al igual que el caso del Grigotá citado por López, tal vez no se trate de los mismos personajes, sino de sus familiares directos: sabemos que, así como el sistema político chanéchiriguano sigue siendo hoy hereditario, los nombres personales también se transmitían entre las generaciones (Bossert \& Villar, 2004). 
Ignoramos todo sobre estas migraciones más antiguas, y en particular sobre el número de personas implicadas. Es permitido pensar que no fueron muy nutridas, y que el escaso número de migrantes no les permitió apoderarse de los «naturales» en épocas muy tempranas. Pues a la llegada de los españoles a la zona (en 1559 con Manso y Nufflo de Chaves), es decir cuando empiezan a aparecer las noticias escritas, todo muestra que el proceso de mestizaje con los naturales y de guaranización lingüística estaba lejos de consumarse. La lengua chané sigue existiendo en la Cordillera (Manso, 2008 [1563]; Padre Martínez en Crónica anónima, 1944 [c. 1600]: 504)18; y Manso por ejemplo pudo encontrar a caciques chanés que todavía estaban al mando de «vasallos» propios (Manso, 2008 [1563]).

No es imposible, en esta perspectiva, que los primeros guaraníes llegados al piedemonte realmente se hayan integrado (y en algunos casos sometido) a los «naturales de los Ilanos». Si bien pudieron representar un peligro hasta para los propios incas, como lo puede sugerir la existencia de los fortines, estas amenazas parecen haber sido puntuales hasta incrementarse solamente en los últimos años de vigencia del imperio incaico. De hecho, la tradicional imagen de una frontera inca oriental solo orientada hacia la guerra contra «los chiriguanaes» no parece corresponderse completamente con la realidad. En términos de Alconini:

«There are reasons to be skeptical of this highly conventional image of the imperial frontier holding back waves of barbarian attacks» (Alconini, 2004: 394).

Primero, no todos estos establecimientos pueden ser calificados de «fortalezas»: es el caso por ejemplo de Samaipata, centro religioso y administrativo más que fortín de guerra; o de Oroncota, pequeño centro provincial orientado a la producción más que a la guerra19. Segundo, hemos visto que bajo el nombre de «chiriguanaes» los incas englobaban a diversos pueblos, y no todos los fortines existentes se hicieron teniendo en mente a los guaraníhablantes de la Cordillera; finalmente, si tomamos en cuenta la época relativamente reciente de las «invasiones» chiriguanaes más masivas, es muy probable que varios de los establecimientos incas de esta frontera fueran erigidos con otros fines que la guerra y diferentes funciones20. De hecho, en el proceso de la «toma de poder» chiriguana, las últimas migraciones, atraídas por el espejismo de Samaipata y Saypurú, fueron al parecer decisivas. Si 5000 chiriguanaes Ilegaron a Grigotá en 1526 según Alcaya, sabemos que más de 2000 indígenas acompañaban a Alejo García en los años 1530 (Díaz de Guzmán, 1835 [1612]: 17). Si es presumible que no todos estos migrantes fueran guaraníes, la situación cambia

18 Véase también Arteaga (1961 [1607]: 183).

19 Alconini $(2002$; 2004) sobre Oroncota; Meyers (1998; 1999) y Meyers \& Ulbert (1997) sobre Samaipata. La denominación de «El Fuerte» aplicada a Samaipata tiene un origen colonial, pues el sitio fue efectivamente ocupado como fortín por los españoles en la segunda mitad del siglo XVI.

20 Martti Pärssinen: Tawantinsuyu: The Inca State and Its Political Organization (1992), citado por Alconini (2004: 393). 
con las migraciones coloniales que acompañan a los conquistadores: 3000 o 3500 guaraníes del Paraguay acompañaron a Domingo de Irala en 154821; entre 15000 y 2500 a Ñuflo de Chaves en 155722; y un total de 5000 entre guaraníes carios de Asunción y guaraníes de Itatín siguieron a Ñuflo de Chaves en 156423. Partiendo del río Guapay en 1548 hacia Lima, Ñuflo de Chaves «halló toda la gente chirigoana de la cordillera que se comían todas las fronteras» (Resolución de los casos, 2008 [1561]: 67)24; según Polo de Ondegardo, fueron los indios traídos por Chaves los que empezaron a destruir la tierra y a someter sus habitantes (Polo de Ondegardo, 1914 [1574]: 89). Esta época parece corresponder a una verdadera toma de poder chiriguana sobre la Cordillera, esbozando la situación que se tornará general en la segunda mitad del siglo XVI.

Así, y si bien empezó poco antes de su llegada, el poder chiriguana parece deber bastante a los mismos españoles de Asunción que, muy a pesar suyo, reforzaron sus líneas con la llegada de miles de nuevos migrantes. «Aliados» de los españoles en Paraguay, los nuevos «chiriguanaes» también lo fueron en la Cordillera (ayudando por ejemplo a Manso a cazar esclavos), lo que no pudo sino reforzar su poder; así, adoptaron tempranamente el uso de la pólvora y las armas de fuego25. En 1557, Jaime Rasquín ponía muchas esperanzas en los chiriguanaes de la Cordillera, considerados como futuros aliados (Rasquín, 2008 [c. 1557]: 43); tanto Condorillo en el Parapetí como Vitupue en el Guapay fueron en efecto aliados de Manso y Chaves: la rebelión solo empezó en 1564 con los asaltos a las poblaciones de la Nueva Rioja y de Nueva Asunción, para no apaciguarse más en toda la Colonia26. Los motivos de esta media vuelta — de la alianza a la guerra - son a todas luces clásicos, y los mismos que impulsaron también los guaraníes del Paraguay, aliados de primera hora, a rebelarse luego contra el español:

«El primer servicio que los guaraníes prestaban en son de reciprocidad y amistad, pronto convirtióse en abuso y opresión» (Susnik, 1965: 3).

En la Cordillera chiriguana también, las encomiendas (en Santa Cruz la Vieja en 1561 o, afectando más a los chiriguanaes, en el Parapetí en 1563) (Manso, 2008 [1563]), la esclavitud incipiente, la evangelización forzosa, etc., provocaron las sublevaciones. Pero lo importante para nuestro propósito no es el «por qué» de las guerras chiriguanas: es el «cómo» y el «cuándo».

21 Schmidel (2008 [1567]: 104) habla de 3000 guaraníes, Díaz de Guzmán (1835 [1612]: 80) de 3 500; Calvete de Estrella (1963 [1571]: 50) de 3000 guaraníes o «cheriones».

22 Fueron 1500 guaraníes según Díaz de Guzmán (1835 [1612]: 114). Otro documento habla de 2 500, de los cuales 1500 habrían vuelto luego al Paraguay después de una pelea contra los indígenas chiquitos (Resolución de los casos, 2008 [1561]: 109).

23 Díaz de Guzmán (1835 [1612]: 133) habla de 2000 carios de Asunción, a los cuales se agregaron 3000 guaraníes de Itatín.

24 El mismo texto en Información de servicios de Nuflo de Chaves (2008 [1561]: 71).

25 Váse, por ejemplo, Arteaga (1961 [1607]).

26 La Información de los chiriguanaes (2008 [1571]: 223-224, 227) indica repetidas veces que los chiriguanaes estaban de paz antes de alzarse en 1564. 
Al hablar del proceso de «demonización» de los chiriguanaes emprendido por el virrey Toledo, Catherine Julien (1997) quiso oponer de cierta manera una visión «peruana» o charqueña (empeñada en justificar la guerra para expandirse al este) con una visión paraguaya de los chiriguanaes, donde estos aparecen como aliados. Sin pretender restar validez a la interpretación de Julien, esta nos parece insuficiente. Ciertamente hubo «demonización», pero las quejas de los oidores de Charcas y los «abominables» adjetivos dados a los chiriguanaes en estos años corresponden también, en mi opinión, a una realidad: a una expansión y sobre todo una toma de poder reciente, en la época colonial, de los chiriguanaes sobre la Cordillera. En 1548, cuando llegó Irala al Guapay, Grigotá se quejó de los abusos de los chiriguanaes; pero también les acaba de vencer en una batalla, y ninguno de los documentos paraguayos relativos a este viaje menciona una presencia chiriguana en «los llanos de los tamacoci», ni mucho menos su encarnizamiento contra los naturales del lugar: la verdadera ruptura, el verdadero inicio del poder chiriguana, es posterior.

En reacción contra esta situación, chanés y demás indígenas llaneros buscaron no pocas veces el apoyo de los españoles — sirvieron de paso, como vimos, como pretexto humanitario a Toledo para hacer la guerra y «defenderlos»—. Grigotá se alió con Manso (López, 1971 [c. 1570]), otros chanés acogieron a Díaz de Guzmán como a su libertador (Díaz de Guzmán, 1979 [1617-1618]: 98-99), sin mucho o ningún éxito: los españoles también querían «piezas» (esclavos), los españoles también querían someterlos. Ya en 1560, los tamacoci intentaron, en vano, sublevarse contra los hombres de Chaves (Información de servicios de Hernando de Salazar, 2008a [1563]: 123). Y, poco más tarde, aparecen nuevas alianzas: los chanés del Parapetí apoyaron a los chiriguanaes en el asalto a la Nueva Rioja de Manso en 1564 (Combès, 2005); en el mismo año, más al norte, los chanés tipionos, los curiobonos y yaconos (también muy probablemente chanés [Información de servicios de Hernando de Salazar, 2008b [1568]: 175])27 y «otros muchos naturales» de los llanos se alzan «con los chiriguanais de la sierra» y su jefe Vitupue: los documentos los llaman «allegados» e incluso «amigos» de Vitupue.

Estas alianzas no pudieron sino facilitar e incrementar aún más el incipiente proceso de mestizaje y de guaranización de los chanés en manos de los chiriguanaes, en calidad de «tributarios» y subordinados. En 1568, un documento evoca de manera sugerente a los «indios chiriguanais tamaguaçis» (Información de servicios de Hernando de Salazar, 2008b [1568]: 179), haciendo ya de ellos un solo grupo. A finales del siglo XVI, los tamacoci como grupo desaparecen de la documentación, «absorbidos» por los chiriguanaes.

Varios parecen haber sido, en definitiva, los mecanismos de la toma de poder chiriguana sobre la Cordillera: el refuerzo de nueva gente llegada en la época

27 Los tipionos son un grupo chané y es muy probable que los curiabonos e yaconos también (su nombre comporta el sufijo pluralizador chané -ono) (véase Combès, 2010; artículos Tipiono, Curiabono, Yacono). El texto de Salazar nombra primero a tipionos, curiabonos e yaconos como aliados de Vitupue, y luego a los amigos chanés del mismo Vitupue, como si fueran las mismas personas. 
colonial con los conquistadores de Asunción; la alianza temprana con los españoles, que facilitó las «cacerías» de esclavos llaneros y un trueque con los españoles, por ejemplo adueñándose muy tempranamente de armas de fuego; y el mestizaje con los mismos indios de los llanos, apoderándose de su sistema político y volcándolo a su favor: a partir de mediados del siglo XVI, los chanés son los «allegados» de Vitupue, el exvasallo del gran Grigotá.

\section{Siglas}

$\begin{array}{ll}\text { ADI } & \text { Archivo del Duque Infante Montesclaros (Madrid) } \\ \text { AGI } & \text { Archivo General de Indias (Sevilla) } \\ & \text { Charcas Audiencia de Charcas } \\ & \text { Lima Audiencia de Lima } \\ & \text { Pat. Patronato } \\ \text { BN Madrid } & \text { Biblioteca Nacional (Madrid) }\end{array}$

\section{Referencias citadas}

ALCONINI, S., 2002 - Prehistoric Inka Frontier Structure and Dynamics in the Bolivian Chaco, 559 pp.; Pittsburg: University of Pittsburg. Ph-D thesis.

ALCONINI, S., 2004 - The southeastern Inka frontier against the Chiriguanos: structure and dynamics of the Inka imperial borderlands. Latin American Antiquity, 15 (4): 389-418.

ARTEAGA, P. de, 1961 [1607] - Relación de todo lo que en el viaje del socorro... In: Cronistas cruceños del Alto Perú Virreinal: 171-183; Santa Cruz: Universidad Autónoma Gabriel René Moreno.

BARCO CENTENERA, M. del, 1969 [1602] - La Argentina o Conquista del río de La Plata. In: Colección de obras y documentos relativos a la historia antigua y moderna de las provincias del río de la Plata (Pedro de Angelis, ed.), t. 3: 1-420; Buenos Aires: Plus Ultra.

BLAS (Negro Blas), 1914 [1585] - Confesión de Blas negro. In: Bolivia-Paraguay, Anexos (Ricardo Mujía, ed.), t. 2: 681-689; La Paz: Imprenta del Estado.

BOSSERT, F. \& VILLAR, D., 2004 - La onomástica chané en clave etnográfica y comparativa. Acta Americana, 12 (1): 49-78.

BROHAN, M. \& HERRERA, E., 2008 - Prólogo de los editores. In: El eco de las voces olvidadas. Una autoetnografía y etnohistoria de los cavineños de la Amazonía boliviana (Alfredo Tabo): 12-45; Copenhague: IWGIA.

CALVETE DE ESTRELLA, J., 1963 [1571] - Rebelión de Pizarro en el Perú y Vida de don P. Gasca, 182 pp.; Madrid.

COMBÈS, I., 2005 - Etno-historias del Isoso. Chané y chiriguanos en el Chaco boliviano (siglos XVI a XX), 396 pp.; La Paz: Instituto Francés de Estudios Andinos, Programa de Investigación Estratégica en Bolivia. 
COMBÈS, I., 2009 - Saypurú: el misterio de la mina oculta, del Inca chiriguano y del dios mestizo. Revista Andina, 48: 185-224.

COMBÈS, I., 2010 - Diccionario étnico. Santa Cruz la Vieja y su entorno en el siglo XVI, 406 рр.; Cochabamba: Itinerarios, Instituto de Misionología.

COMBÈS, I., 2011 - El Paititi, los Candires y las migraciones guaraníes. Suplemento Antropológico; Asunción (en prensa).

COMBÈS, I. \& HIRTZEL, V., 2007 - Apuntes sobre los tamacocis. In: Anuario de estudios bolivianos, archivísticos y bibliográficos; Sucre (en prensa).

COMBÈS, I. \& LOWREY, K., 2006 - Slaves without masters? Arawakan dynasties among the Chiriguano (Bolivian Chaco, XVI-XX centuries). Ethnohistory, 53 (4): 689-714.

COMBÈS, I. \& SAIGNES, T., 1991 - Alter Ego. Naissance de l'identité chiriguano, 152 pp.; París: EHESS, Cahiers de l'Homme.

COMBÈS, I. \& VILLAR, D., 2004 - Aristocracias chané. «Casas» en el Chaco argentino y boliviano. Journal de la Société des Américanistes, 90 (2): 63-102.

CRÓNICA ANÓNIMA, 1944 [c. 1600] - Crónica anónima. In: Historia General de la Compañía de Jesús en la provincia del Perú (P. Mateos, ed.): 471-507; Madrid.

DÍAZ DE GUZMÁN, R., 1835 [1612] - Historia argentina del descubrimiento, población y conquista de las provincias del río de la Plata. In: Colección de obras y documentos relativos a la historia antigua y moderna de las provincias del río de la Plata (Pedro de Angelis, ed.), t. 1: 1-156; Buenos Aires: Imprenta del Estado.

DÍAZ DE GUZMÁN, R., 1979 [1617-1618] - Relación de la entrada a los Chiriguanos, 173 pp.; Santa Cruz: Fundación cultural «Ramón Darío Gutiérrez».

DISCURSO..., 1906 [s/f] - Discurso de la sucesión y gobierno de los Yngas. In: Juicio de Límites entre el Perú y Bolivia. Prueba Peruana Presentada al gobierno de la República Argentina (V. Maurtua, ed.), vol. 8: 149-165; Madrid: Imp. de los hijos de M. G. Hernández.

GANDIA, E. de, 1929 - Historia del Gran Chaco, 209 pp.; Madrid, Buenos Aires: Ed. J. Roldán y Cia.

GANDIA, E. de, 1935 - Historia de Santa Cruz de la Sierra. Una nueva república en Sudamérica, 153 pp.; Buenos Aires: talleres gráficos argentinos de L. J. Rosso.

GARCILASO DE LA VEGA, I., 1990 [1609] - Comentarios Reales, 283 pp.; México: Ed. Porrúa S. A.

INFORMACIÓN DE LOS CHIRIGUANAES, 2008 [1571] - Información de los chiriguanaes. In: Desde el Oriente. Documentos para la historia del Oriente boliviano y Santa Cruz la Vieja (1542-1597) (C. Julien, ed.): 222-234; Santa Cruz: Fondo Editorial Municipal.

INFORMACIÓN DE SERVICIOS DE GONZALO SOLÍS DE HOLGUÍN, 1914 [1603] Información de servicios de Gonzalo Solís de Holguín. In: Bolivia-Paraguay. Anexos (R. Mujía, ed.), t. 3: 65-103; La Paz: Imprenta El Tiempo.

INFORMACIÓN DE SERVICIOS DE HERNANDO DE SALAZAR, 2008a [1563] - Información de servicios de Hernando de Salazar. In: Desde el Oriente. Documentos para la historia del Oriente boliviano y Santa Cruz la Vieja (1542-1597) (C. Julien, ed.): 119159; Santa Cruz: Fondo Editorial Municipal.

INFORMACIÓN DE SERVICIOS DE HERNANDO DE SALAZAR, 2008b [1568] - Copia de una información de servicios de Hernando de Salazar. In: Desde el Oriente. Documentos para la historia del Oriente boliviano y Santa Cruz la Vieja (1542-1597) (C. Julien, ed.): 170-211; Santa Cruz: Fondo Editorial Municipal. 
INFORMACIÓN DE SERVICIOS DE ÑUFLO DE CHAVES, 2008 [1561] - Información de servicios de Ñuflo de Chaves. In: Desde el Oriente. Documentos para la historia del Oriente boliviano y Santa Cruz la Vieja (1542-1597) (C. Julien, ed.): 70-93; Santa Cruz: Fondo Editorial Municipal.

IRALA MARTÍNEZ, D. de, 2008 [1543] - Relación de la jornada al norte. In: Desde el Oriente. Documentos para la historia del Oriente boliviano y Santa Cruz la Vieja (1542-1597) (C. Julien, ed.): 1-11; Santa Cruz: Fondo Editorial Municipal.

JULIEN, C., 1997 - Colonial perspectives on the Chiriguaná (1528-1574). In: Resistencia y adaptación nativas en las tierras bajas latinoamericanas (M. S. Cipolletti, ed.): 17-76; Quito: Abya-Yala.

JULIEN, C., 2005 - Alejo García en la historia. Anuario de Estudios Bolivianos, Archivísticos y Bibliográficos, 11: 223-266; Sucre.

LANGER, P., 2010 - Piores que bestas feras: Garcilaso de la Veja e o imaginário hispânoInca sobre os Chiriguanos. Topoi. Revista de Historia, n. ${ }^{\circ}$ 21, vol. 11: 5-22.

LANGER, P., 2011 - Etimologia dos etnônimos atribuídos aos Guarani do Paraguai e da Cordilheira chiriguana. XXVI Simpósio Nacional de História da ANPUH; Sao Paulo, 17-22 de julho de 2011.

LEVILLIER, R. (ed.) 1922 - La Audiencia de Charcas. Correspondencia de presidentes y oidores, 3 tomos; Madrid: Colección de publicaciones históricas de la Biblioteca del Congreso argentino.

LIZÁRRAGA, R. de, 1968 [c. 1600] - Descripción breve de toda la tierra del Perú, Tucumán, Río de la Plata y Chile, 213 pp.; Madrid.

LÓPEZ, P., 1971 [c. 1570] - Relación de Pero López. Visión de un conquistador del siglo XVI (R. Güenaga de Silva, ed.), 120 pp.; Bahía Blanca: Universidad del Sur (Gabinete de investigación de historia americana y argentina, departamento de humanidades).

MANSO, A., 2008 [1563] - Encomiendas hechas por Andrés Manso. In: Desde el Oriente. Documentos para la historia del Oriente boliviano y Santa Cruz la Vieja (1542-1597) (C. Julien, ed.): 160-164; Santa Cruz: Fondo Editorial Municipal.

MÉTRAUX, A., 1927 - Les migrations historiques des Tupi-Guaraní. Journal de la Société des Américanistes, 19: 1-45.

MÉTRAUX, A., 1930 - Études sur la civilisation des indiens Chiriguano. Revista del Instituto de Etnología de la Universidad Nacional de Tucumán, t. 1: 295-493.

MEYERS, A., 1998 - Las campañas arqueológicas en Samaipata, 1994-1996. Segundo informe de trabajo. Boletín de la Sociedad de Investigación del Arte Rupestre de Bolivia, 12: 59-86.

MEYERS, A., 1999 - Reflexiones acerca de la periodización de la cultura inka: perspectivas desde Samaipata, oriente de Bolivia. In: Actas del XII congreso nacional de arqueología argentina (C. Diez Marín, ed.), t. 1: 239-251; La Plata, Buenos Aires: Universidad Nacional de La Plata.

MEYERS, A. \& COMBÈS, I., 2011 - La Relación Cierta de Alcaya(ga). In: Paititi. Ensayos y documentos (I. Combès \& V. Tyuleneva, eds.): 158-171; Cochabamba: Itinerarios, Instituto de Misionología.

MEYERS, A. \& ULBERT, C., 1997 - Inka Archaeology in Eastern Bolivia: Some Aspects of the Samaipata Project. Tawantinsuyu, 3: 79-85.

MINGO DE LA CONCEPCIÓN, M., 1981 [1791] - Historia de las misiones franciscanas de Tarija entre Chiriguanos, 447 pp.; Tarija: Universidad boliviana «Juan Misael Saracho».

MUJíA, R. (ed.), 1914 - Bolivia-Paraguay y Anexos, 9 tomos; La Paz: Imprenta del Estado. 
NORDENSKIÖLD, E., 1917 - The Guarani invasion of the Inca empire in the sixteenth century: an historical Indian migration. The Geographical Review, 4 (2): 103-121.

NORDENSKIÖLD, E., 1920 - The Changes in the Material Culture of Two Indian Tribes under the influence of New Surroundings, Vol. 2; Göteborg: Comparative Ethnographical Studies.

PÄRSSINEN, M., 2003 - ¿Cuándo empezó, realmente, la expansión guaraní hacia las vertientes andinas orientales? In: Andes orientales y Amazonía occidental. Ensayos entre la historia y la arqueología de Bolivia, Brasil y Perú (M. Pärssinen \& A. Siiriänen, eds.): 213-232; La Paz: Maestría en Historias andinas y amazónicas, Universidad Mayor de San Andrés, Colegio nacional de Historiadores de Bolivia, Producciones CIMA.

POLO DE ONDEGARDO, J., 1914 [1574] - Informe sobre el origen y costumbres de los chiriguanos. In: Bolivia-Paraguay y Anexos (R. Mujía, ed.), t. 2: 82-98; La Paz: Imprenta del Estado.

RASQUÍN, J., 2008 [c. 1557] - Petición de Jaime Rasquín. In: Desde el Oriente. Documentos para la historia del Oriente boliviano y Santa Cruz la Vieja (1542-1597) (C. Julien, ed.): 41-44; Santa Cruz: Fondo Editorial Municipal.

RELACIÓN DE LOS SERVICIOS DE ÑUFLO DE CHAVES Y ÁlVARO DE CHAVES, 2008 [1588] - Relación de los servicios de Ñuflo de Chávez y Álvaro de Chávez. In: Desde el Oriente. Documentos para la historia del Oriente boliviano y Santa Cruz la Vieja (1542-1597) (C. Julien, ed.): 240-273; Santa Cruz: Fondo Editorial Municipal.

RELACIÓN VERDADERA, 2008 [1571] - Relación verdadera del asiento de Santa Cruz de la Sierra. In: Desde el Oriente. Documentos para la historia del Oriente boliviano y Santa Cruz la Vieja (1542-1597) (C. Julien, ed.): 212-217; Santa Cruz: Fondo Editorial Municipal.

REPARTIMIENTO, 2008 [1561] - Repartimiento que se hizo por Ñuflo de Chávez de la tierra y solares de la dicha ciudad de Santa Cruz de la Sierra. In: Desde el Oriente. Documentos para la historia del Oriente boliviano y Santa Cruz la Vieja (1542-1597) (C. Julien, ed.): 99-109; Santa Cruz: Fondo Editorial Municipal.

RESOLUCIÓN DE LOS CASOS, 2008 [1561] - Resolución de los casos ofrecidos al capitán Ñuflo de Chávez desde el año 57. In: Desde el Oriente. Documentos para la historia del Oriente boliviano y Santa Cruz la Vieja (1542-1597) (C. Julien, ed.): 109-113; Santa Cruz: Fondo Editorial Municipal.

RICHARD, N., 2008 - Les chiens, les hommes et les étrangers furieux. Archéologie des identités indiennes dans le Chaco boréal, 713 pp.; París: EHESS. Thèse de doctorat en Anthropologie.

SAIGNES, T., 2007 - Historia del pueblo chiriguano, 332 pp.; La Paz: Instituto Francés de Estudios Andinos, Plural Editores, IRD, Embajada de Francia.

SANABRIA FERNÁNDEZ, H., 1949 - Los chanés. Boletín de la sociedad de estudios geográficos e históricos de Santa Cruz, 29-30: 5-41; Santa Cruz de la Sierra.

SANABRIA FERNÁNDEZ, H., 1961 - Introducción y notas a la Relación de Diego Felipe de Alcaya. In: Cronistas cruceños del Alto Perú Virreinal: 37-46, 69-86; Santa Cruz: Universidad Autónoma Gabriel René Moreno.

SÁNCHEZ, T., 1906 [s/f] - Relación de lo que parece conviene al servicio de S. M. In: Juicio de Límites entre el Perú y Bolivia. Prueba Peruana presentada al Gobierno de la República argentina (V. M. Maurtua, ed.), t. 3: 36-47; Barcelona: Imprenta de Heinrich y Comp. 
Grigotá y Vitupue. En los albores de la historia chiriguana (1559-1564)

SÁNCHEZ LABRADOR, J., 1910 [c. 1770] - El Paraguay católico, 2 tomos; Buenos Aires: Imprenta de Coni Hermanos.

SCHMIDEL, U., 2008 [1567] - Reise in die La Plata-Gegend (1534-1544)/Viaje al río de La Plata y Paraguay, 266 pp.; Kiel: Westensee-Verlag (Fontae Americanae 3).

SUÁREZ DE FIGUEROA, L., 1965 [1586] - Relación de la ciudad de Santa Cruz de la Sierra. In: Relaciones geográficas de Indias I (M. Jiménez de la Espada, ed.): 402406; Madrid.

SUSNIK, B., 1965 - El indio colonial del Paraguay. El guaraní colonial, 243 pp.; Asunción: Museo etnográfico Andrés Barbero.

SUSNIK, B., 1968 - Chiriguanos I. Dimensiones etnosociales, 269 pp.; Asunción: Museo etnográfico Andrés Barbero.

SUSNIK, B., 1978 - Los aborígenes del Paraguay I. Etnología del Chaco boreal y su periferia (siglos XVI y XVII), 156 pp.; Asunción: Museo etnográfico Andrés Barbero.

TESTIMONIO Y RELACIÓN, 2008 [1561] - Testimonio y relación de toda la tierra. In: Desde el Oriente. Documentos para la historia del Oriente boliviano y Santa Cruz la Vieja (1542-1597) (C. Julien, ed.): 113-117; Santa Cruz: Fondo Editorial Municipal.

TOLEDO, F. de, 1914 [1571] - Instrucciones a Juan Pérez de Zurita. In: Bolivia-Paraguay y Anexos (R. Mujía, ed.), t. 2: 27-28; La Paz: Imprenta del Estado.

TOLEDO, F. de, 2008 [1573] - Gastos con los chiriguanaes que salieron de paz. In: Desde el Oriente. Documentos para la historia del Oriente boliviano y Santa Cruz la Vieja (1542-1597) (C. Julien, ed.): 235-239; Santa Cruz: Fondo Editorial Municipal. 